Article

\title{
Dual-Functioning Antibacterial Eugenol-Derived Plasticizers for Polylactide
}

\author{
Wenxiang Xuan, Karin Odelius and Minna Hakkarainen *(D) \\ Department of Fibre and Polymer Technology, School of Engineering Sciences in Chemistry, Biotechnology and \\ Health, KTH Royal Institute of Technology, Teknikringen 56, 10044 Stockholm, Sweden; wxuan@kth.se (W.X.); \\ hoem@kth.se (K.O.) \\ * Correspondence: minna@kth.se
}

Received: 29 May 2020; Accepted: 16 July 2020; Published: 20 July 2020

\begin{abstract}
Dual-functioning additives with plasticizing and antibacterial functions were designed by exploiting the natural aromatic compound eugenol and green platform chemical levulinic acid or valeric acid that can be produced from biobased resources. One-pot synthesis methodology was utilized to create three ester-rich plasticizers. The plasticizers were thoroughly characterized by several nuclear magnetic resonance techniques $\left({ }^{1} \mathrm{H}\right.$ NMR, ${ }^{13} \mathrm{C}$ NMR, ${ }^{31} \mathrm{P}$ NMR, HSQC, COSY, HMBC) and by electrospray ionization-mass spectrometry (ESI-MS) and their performances, as plasticizers for polylactide (PLA), were evaluated. The eugenyl valerate was equipped with a strong capability to depress the glass transition temperature $\left(T_{\mathrm{g}}\right)$ of PLA. Incorporating $30 \mathrm{wt} \%$ plasticizer led to a reduction of the $T_{\mathrm{g}}$ by $43{ }^{\circ} \mathrm{C}$. This was also reflected by a remarkable change in mechanical properties, illustrated by a strain at break of $560 \%$, almost 110 times the strain for the breaking of neat PLA. The two eugenyl levulinates also led to PLA with significantly increased strain at breaking. The eugenyl levulinates portrayed higher thermal stabilities than eugenyl valerate, both neat and in PLA blends. The different concentrations of phenol, carboxyl and alcohol functional groups in the three plasticizers caused different bactericidal activities. The eugenyl levulinate with the highest phenol-, carboxyl- and alcohol group content significantly inhibited the growth of Staphylococcus aureus and Escherichia coli, while the other two plasticizers could only inhibit the growth of Staphylococcus aureus. Thus, the utilization of eugenol as a building block in plasticizer design for PLA illustrated an interesting potential for production of additives with dual functions, being both plasticizers and antibacterial agents.
\end{abstract}

Keywords: plasticizer; polylactide; eugenol; levulinic acid; antibacterial

\section{Introduction}

The increasing demand for food, due to the increase in world population and the long-distance logistic chains, has prompted amplified requirements of food freshness. A prolonged shelf-life is highly desired if the nutrition of the food is not to be a trade-off. Innovative materials with delicately designed functions and targeting food packaging could provide solutions. Green building blocks that can be achieved from renewable biomass conversions in a commercial scale should be utilized in the design of the high-performance materials. If agricultural and food waste is used as converted biomass, green features of the building blocks will be further accentuated, contributing to a more sustainable engineering production for the society.

Polylactide (PLA), as a biodegradable replacement for commodity plastics, has been widely studied in the applications of packaging and has demonstrated the capability of maintaining food quality and light protection [1-6]. The U.S. Food and Drug Administration (FDA) has approved PLA to be used in food-contact packaging [7], therefore, the commercial utilization of PLA packaging has been 
increasingly realized [8]. To extend the shelf-life of food products, the microbiological contaminations inside the packaging need to be inhibited or minimized. Incorporating antimicrobial agents in the packaging is the simplest and most feasible means to achieve that aim and those agents can either be present as independent devices or be part of the packaging material itself [9]. Many antimicrobial agents have been evaluated as additives in PLA to examine the final antimicrobial performances, including catechin [10], nisin [11,12], copper nanoparticles [13], silver-based nanoclay [14], preservatives [15], lauric arginate [16], essential oil [17], thymol [18], natamycin [19], triclosan [20] and chitosan [21].

However, with the addition of antimicrobial agents, the mechanical and thermal properties of PLA are unavoidably altered. This can be critical for a packaging material, because PLA is generally a rigid and semicrystalline polymer and usually requires processing aids for flexible applications. Plasticizers are chemical additives that lower the glass transition temperature $\left(T_{\mathrm{g}}\right)$ of plastics and improve ductility for easier processing. When plasticizer is blended with polymer, the chain mobility is facilitated, leading to decreased $T_{\mathrm{g}}$. As a result, other properties of the polymer that relate to chain mobility can be influenced, such as the crystallization process of polymer, which plays a critical role for the mechanical and thermal behaviors of polymer [22]. The performance of the plasticizer depends on several factors, including the molecular weight of plasticizer, chemical structure (e.g., balance between polar and nonpolar groups), linear or branched shape, flexibility of plasticizer chain and amount added [23]. Both the molecular weight and chemical structure influence the miscibility of the plasticizer with the polymer. Polar groups, such as ester groups, are usually required for forming strong secondary interactions between plasticizer and the polymer, while nonpolar groups often enhance the plasticization. Miscibility is desired for obtaining homogeneous and migration resistant polymer blends with reduced $T_{g}$. Plasticizers with a lower molecular weight often have higher plasticizing efficiency but lower migration-resistance.

Several PLA plasticizers have been designed in previous works with various purposes, for instance for increased migration-resistance [24-26] or from renewable starting materials [24,27,28]. Citrates that can be produced from biobased starting materials, for example acetyl triethyl citrate and triethyl citrate, are recommended by the FDA to be used as plasticizers in food-packaging material [29]. In addition, the alkylsulfonic acid ester of phenol, another FDA-approved food-contact plasticizer [30], indicated the potential for the utilization of versatile building blocks in plasticizer design. This includes phenolic compounds that simultaneously also can act as antioxidants [31,32] and biocompatibilizers [33] in polymeric packaging materials. Nevertheless, some phenolic compounds have demonstrated cytotoxicity on mammalian cells and have aroused health concerns about their uses [34-36]. In addition to the mammalian toxicity, the biodegradation of plasticizers is another important issue when evaluating the full life-cycle of plastics. Nonbiodegradable plasticizers can create environmental contaminations and lead to problematic bioaccumulation [37-40]. Thus, comprehensive evaluations including toxicity and biodegradation tests are essential to ensure the plasticizers have no negative effect on human health and the environment.

Plasticizers with dual functions including plasticization ability and antibacterial properties would be a promising solution for flexible PLA packaging, providing longer shelf-life for the food. To achieve that goal, the realization of the benefits should be reflected in the considerations of plasticizer design. Levulinic acid, a green platform chemical, has demonstrated great miscibility and plasticization of PLA in its ester forms [28]. Valeric acid that can be produced by biomass conversion is also a good candidate to be utilized in plasticizer design since pentaerythritol tetravalerate has been approved by the FDA for use as a food-contact plasticizer [30]. Furthermore, eugenol, a natural phenolic compound exhibiting antimicrobial properties [41], has illustrated good potential in the development of high-performance materials [42]. Therefore, we anticipated that plasticizers designed from eugenol, levulinic acid and valeric acid, could have good plasticizing effects on PLA, while also providing antibacterial protections. 


\section{Materials and Methods}

\subsection{Materials}

Levulinic acid (LeA; 97\%), valeric acid (VaA; 99\%), eugenol (99\%) and $p$-toluene sulfonic acid monohydrate (PTSA; 98.5\%) for the synthesis of plasticizers were purchased from Sigma-Aldrich and were not produced in a biobased way. Potassium carbonate (ACS grade; Arcos) and ethyl acetate (analytical reagent grade; Fisher Scientific) were utilized to remove unreacted eugenol and levulinic or valeric acids and to extract the plasticizers. $\mathrm{N}, \mathrm{N}$-Dimethylformamide (DMF; 99.8\%; VWR) and pyridine (99.7\%; VWR) were employed in ${ }^{31} \mathrm{P}$ nuclear magnetic resonance (NMR) spectroscopy analyses in which $N$-hydroxy-5-norbornene-2,3-dicarboxylic acid imide (NHND; 97\%; Sigma-Aldrich) and chromium (III) acetylacetonate (99.99\% trace metal basis; Sigma-Aldrich) were incorporated as an internal standard and relaxation reagent, respectively. The derivatizing reagent was 2-chloro-4,4,5,5-tetramethyl-1,3,2-dioxaphospholane (TMDP; 95\%; Sigma-Aldrich). Chloroform-d ( $\left.\mathrm{CDCl}_{3} ; 99.8 \%\right)$, from Cambridge Isotope Laboratories, was used in all NMR analyses. Dichloromethane (HPLC grade; Fisher Scientific) and polylactide (5200D; NatureWorks; $\mathrm{M}_{\mathrm{n}}=118,000 \mathrm{~g} / \mathrm{mol}, \mathrm{D}=1.7$ ) were used to prepare polylactide blends with or without plasticizers by solution casting. Methanol (hypergrade for LC-MS; Merck) served as solvent for electrospray ionization-mass spectrometry (ESI-MS) analysis. Regarding antibacterial evaluation, LB broth and agar were provided by Sigma-Aldrich and qualitative filter papers and ethanol absolute were purchased from VWR. All chemicals were used as received.

\subsection{Synthesis of Plasticizers}

Two eugenyl levulinates (TL and ML) were synthesized through reactions between LeA and eugenol. TL was prepared in a molar ratio of 3:1 for eugenol:LeA and ML was prepared in an equal molar ratio (1:1). LeA ( $3.5 \mathrm{~g}, 0.03 \mathrm{~mol})$ and eugenol $(14.8 \mathrm{~g}, 0.09 \mathrm{~mol})$ were used to synthesize TL and LeA (11.6 g, $0.1 \mathrm{~mol})$ and eugenol $(16.4 \mathrm{~g}, 0.1 \mathrm{~mol})$ to generate ML. An eugenyl valerate (MV) was derived from VaA $(5.1 \mathrm{~g}, 0.05 \mathrm{~mol})$ and eugenol $(8.21 \mathrm{~g}, 0.05 \mathrm{~mol})$. In addition, eugenol was reacted alone with catalyst as a control experiment $(8.21 \mathrm{~g}, 0.05 \mathrm{~mol})$. All reactions were catalyzed by $1 \mathrm{~mol} \%$ PTSA equivalent to eugenol. The reagents were stirred and reacted in a $250 \mathrm{~mL}$ three-necked round-bottomed flask at $140{ }^{\circ} \mathrm{C}$ for $24 \mathrm{~h}$ under nitrogen atmosphere. The flask was connected to a Liebig condenser equipped with a $25 \mathrm{~mL}$ round-bottomed flask to remove and collect the formed water during reaction. At the end of the reaction time, the reaction liquor was cooled to $22{ }^{\circ} \mathrm{C}$ and mixed with $20 \mathrm{~mL}$ water with vigorous stirring. Then, $20 \mathrm{wt} \% \mathrm{~K}_{2} \mathrm{CO}_{3}$ (aq.) was added into the mixture with vigorous stirring until $\mathrm{pH}>12$. The plasticizers in alkaline mixture were later extracted by ethyl acetate in a separation funnel. The desired ethyl acetate phase was separated and further purified with $\mathrm{K}_{2} \mathrm{CO}_{3}$ dilution $(\mathrm{pH}>12)$ twice to remove eugenol residue completely, followed by three repetitions of an extraction process with deionized water to remove alkali residue. The plasticizers were recovered by rotary evaporation of ethyl acetate at reduced pressure.

\subsection{Nuclear Magnetic Resonance (NMR)}

The main linkages in the synthesized plasticizers were determined by $1 \mathrm{D}-\mathrm{NMR}\left({ }^{1} \mathrm{H}\right.$ NMR, ${ }^{13} \mathrm{C}$ NMR, ${ }^{31} \mathrm{P}$ NMR) and 2D-NMR (HSQC, COSY, HMBC). All analyses were completed by a Bruker Avance 400 spectrometer at $25^{\circ} \mathrm{C}$. The frequency of the equipment was 400,100 and $162 \mathrm{MHz}$ for ${ }^{1} \mathrm{H}$ NMR, ${ }^{13} \mathrm{C}$ NMR and ${ }^{31} \mathrm{P}$ NMR respectively. Two scans, 16 dummy scans and a relaxation time of $1.5 \mathrm{~s}$ were applied in HSQC and 4 scans, 8 dummy scans and a relaxation time of $2 \mathrm{~s}$ were used for COSY. Regarding HMBC, 4 scans, 16 dummy scans and a relaxation time of $1.5 \mathrm{~s}$ were utilized. The chloroform residue in chloroform-d was utilized as an internal reference to calibrate all the spectra (except ${ }^{31} \mathrm{P}$ NMR) and phase corrections on both directions were processed on HSQC and COSY spectra. The procedures of ${ }^{31} \mathrm{P}$ NMR analyses were described individually. In the preparation of each ${ }^{31} \mathrm{P}$ NMR sample, around $30 \mathrm{mg}$ synthesized plasticizers was mixed in sequence with $100 \mu \mathrm{L}$ DMF, $100 \mu \mathrm{L}$ 
pyridine, $50 \mu \mathrm{L}$ stock solution of internal standard $(60 \mathrm{mg} / \mathrm{mL}$ NHND and $10 \mathrm{mg} / \mathrm{mL}$ chromium acetylacetonate in pyridine) and $400 \mu \mathrm{L}$ chloroform-d in a glass vial. Next, $100 \mu \mathrm{L}$ TMDP was added into the vial and the mixture was left on an orbital shaker for $30 \mathrm{~min}$ to react. Then, ${ }^{31} \mathrm{P}$ NMR analyses were conducted with following parameters-256 scans, 4 dummy scans and a relaxation time of $6 \mathrm{~s}$. The peak from water reacted with TMDP $\left(\delta_{\mathrm{P}}=132.2 \mathrm{ppm}\right)$ was taken as the internal reference. All data were processed by MestReNova v9.0.0 software.

\subsection{Electrospray Ionization Mass Spectrometry (ESI-MS)}

The synthesized plasticizers were analyzed by a Finnigan LCQ ion trap mass spectrometer in positive mode. The plasticizers were diluted in methanol to a concentration below $0.1 \mathrm{mM}$. The diluted solution was pumped in by a syringe with a speed of $25 \mu \mathrm{L} / \mathrm{min}$ and the ion source was set to $4.5 \mathrm{kV}$. The capillary temperature was adjusted to $200^{\circ} \mathrm{C}$. The nebulizing gas was nitrogen.

\subsection{Preparation of PLA Films}

The neat PLA film and plasticized PLA films were obtained by solution casting in petri dishes with a diameter of $186 \mathrm{~mm}$. The granular PLA was dissolved in $100 \mathrm{~mL}$ dichloromethane either alone or with 10, 20 or $30 \mathrm{wt} \%$ plasticizers (in total weight) to produce neat and plasticized PLA films. The total weight of polymer or polymer-plasticizer set was $4.0 \mathrm{~g}$. The polymer solution was stirred at $22{ }^{\circ} \mathrm{C}$ for at least $1.5 \mathrm{~h}$ before pouring into petri dishes. The petri dish was kept in a fume hood at $22{ }^{\circ} \mathrm{C}$ for at least 3 days and later the film was removed from the petri dish. The remaining solvent traces in the films were removed in a drying chamber at $25{ }^{\circ} \mathrm{C}$ with reduced pressure for at least 4 days. The thickness of a typical film was $151 \pm 19 \mu \mathrm{m}$. The plasticized PLA films were denoted as "weight fraction of plasticizer + abbreviation of plasticizer name" (e.g., $30 \mathrm{MV}$ represented the PLA film that had been plasticized by $30 \%$ MV plasticizer). The neat PLA film was referred to as PLA100.

\subsection{Differential Scanning Calorimetry (DSC)}

The glass transition temperatures $\left(T_{g}\right)$ of the neat and plasticized PLA films were assessed by Mettler Toledo DSC 820 Module in nitrogen atmosphere. The DSC program consisted of a scan cycle (25-200 ${ }^{\circ} \mathrm{C}$, kept for $2 \mathrm{~min} \rightarrow-30{ }^{\circ} \mathrm{C}$, kept for $2 \mathrm{~min}$ ) to remove thermal history and a following second heating scan $\left(-30-200^{\circ} \mathrm{C}\right)$. The cooling and heating rates were set to $10^{\circ} \mathrm{C}$ per minute and the midpoint of glass transition in the second heating scan was extracted as the $T_{g}$. Triplicate samples were analyzed.

\subsection{Thermal Gravimetric Analysis (TGA)}

The thermal stabilities of the neat plasticizers and plasticized PLA films were measured by using a Mettler Toledo TGA/DSC 851e module instrument. The elevating heating scan was $25^{\circ} \mathrm{C}$ to $500{ }^{\circ} \mathrm{C}$ with a heating rate of $5{ }^{\circ} \mathrm{C}$ per second. Nitrogen atmosphere was provided by a $50 \mathrm{~mL} / \mathrm{min}$ nitrogen flow. Triplicate samples were analyzed. The onset temperature corresponding to weight loss of $5 \%$ was taken for comparison.

\subsection{Tensile Test}

The mechanical performances of neat and plasticized PLA films were evaluated by tensile test on INSTRON 5944 module equipped with pneumatic grips. The PLA films were cut into rectangular specimens with a constant width of $5 \mathrm{~mm}$ and a length of roughly $100 \mathrm{~mm}$. The thickness of specimen was measured by digimatic indicator (ID-C112B, Mitutoyo Corp., Kawasaki, Japan) with resolution of $0.001 \mathrm{~mm}$. The thickness values at two ends and middle position of the specimen were averaged as the mean thickness of that specimen. All specimens were conditioned before testing for $40 \mathrm{~h}$ at RH $50 \pm 5 \%$ and $23{ }^{\circ} \mathrm{C} \pm 1{ }^{\circ} \mathrm{C}$, as required in ASTM D618-13 (Standard Practice for Conditioning Plastics for Testing). A load cell of maximum $500 \mathrm{~N}$ was set at a crosshead speed of $20 \mathrm{~mm} / \mathrm{min}$ and the length between gauges was $20 \mathrm{~mm}$. Data from at least 6 specimens were processed for each sample. 


\subsection{Zone of Inhibition Test}

The potential migration and antibacterial effect of the synthesized plasticizers were examined by zone of inhibition test on Staphylococcus aureus (DSM 2569) and Escherichia coli (ORN 178). The PLA disks blended with plasticizers, filter paper disks loaded with plasticizers and the original plasticizers alone were assessed for antibacterial performances. All disks were of a diameter of $9 \mathrm{~mm}$. To obtain filter paper loaded with $1 \mathrm{mg}$ plasticizers, a dilution of plasticizers in $75 \mathrm{vol} \%$ ethanol with a concentration of $0.1 \mathrm{~g} / \mathrm{mL}$ was prepared in prior to adding $10 \mu \mathrm{L}$ dilution on a paper disk by pipette. This was repeated five times to prepare disks loaded with $5 \mathrm{mg}$ plasticizers. The disks were subsequently dried thoroughly between each plasticizer addition. All control paper disks without plasticizers were treated with $75 \mathrm{vol} \%$ ethanol with the same preparation process as the disks loaded with plasticizers and dried completely before use. The bacteria were incubated in LB broth overnight and then diluted with saline for further use. A volume of $500 \mu \mathrm{L}$ of bacteria dilution, equivalent to $8.5 \times 10^{5} \mathrm{CFU}$ Staphylococcus aureus or $3.5 \times 10^{5} \mathrm{CFU}$ Escherichia coli, was inoculated on each LB agar plate. The disks or neat plasticizers were placed on top of the inoculated agar plates. The petri dishes were incubated for at least $18 \mathrm{~h}$ at $37^{\circ} \mathrm{C}$ before examination. The diameters of inhibition zones were measured by Cocraft ${ }^{\circledR}$ vernier caliper.

\section{Results \& Discussion}

Eugenol, an aromatic biobased substance with antibacterial properties, levulinic acid, an abundant green platform chemical [43], along with biobased valeric acid, are versatile building blocks that have high potential in the design of ecofriendly property-enhancing additives for PLA. A series of biobased ester-type compounds were, thus, synthesized based on these three starting chemicals, forming a variety of chemical bonds due to the diverse reactivities. The synthesized compounds were thoroughly characterized and their potential dual functions combining plasticization and introduction of antibacterial properties in PLA were examined.

\subsection{Synthesis and Chemical Structure of the Plasticizer Candidates}

Three plasticizer candidates that can be derived from biobased resources, two eugenyl levulinates (ML and TL) and eugenyl valerates (MV), with aliphatic and phenolic ester functionalities, were successfully synthesized from eugenol and levulinic acid or valeric acid under classic esterification conditions (protonic catalyst and high temperature). The yield for MV, ML and TL was $65.2 \%, 67.4 \%$ and $77.4 \%$, respectively. All three plasticizer candidates were mixtures of esters with different molecular weights. This is because several types of reactions occurred simultaneously, including esterification, electrophilic aromatic substitution and nucleophilic addition, resulting in several different linkages in the plasticizer candidates (Figure 1). The C-O and C-C linkages in eugenol contributed to the formation of diverse products during synthesis of MV. Additional reactions took place during the synthesis of ML and TL as carbonyl carbons of the ketones from levulinic acid reacted with the eugenol rings by nucleophilic additions.

The versatile reactivity of eugenol and levulinic acid resulted in a broad distribution of reaction products as shown by the ESI-MS analysis presented in Figure 2. To further fingerprint the formed products, two-dimensional NMR, together with one-dimensional NMR, was utilized as an essential tool to examine the main linkages existing in the plasticizer candidates MV, ML and TL and in the product formed during a control reaction with only eugenol (Figures S1-S21). The peak integrations and assignments for one-dimensional NMR spectra, Tables S1 and S2, and peak assignments for ESI-MS, Tables S3-S6, jointly supported the structural assignment. The results of the analyses are presented in brief below, while more details are presented in Supporting Information. 


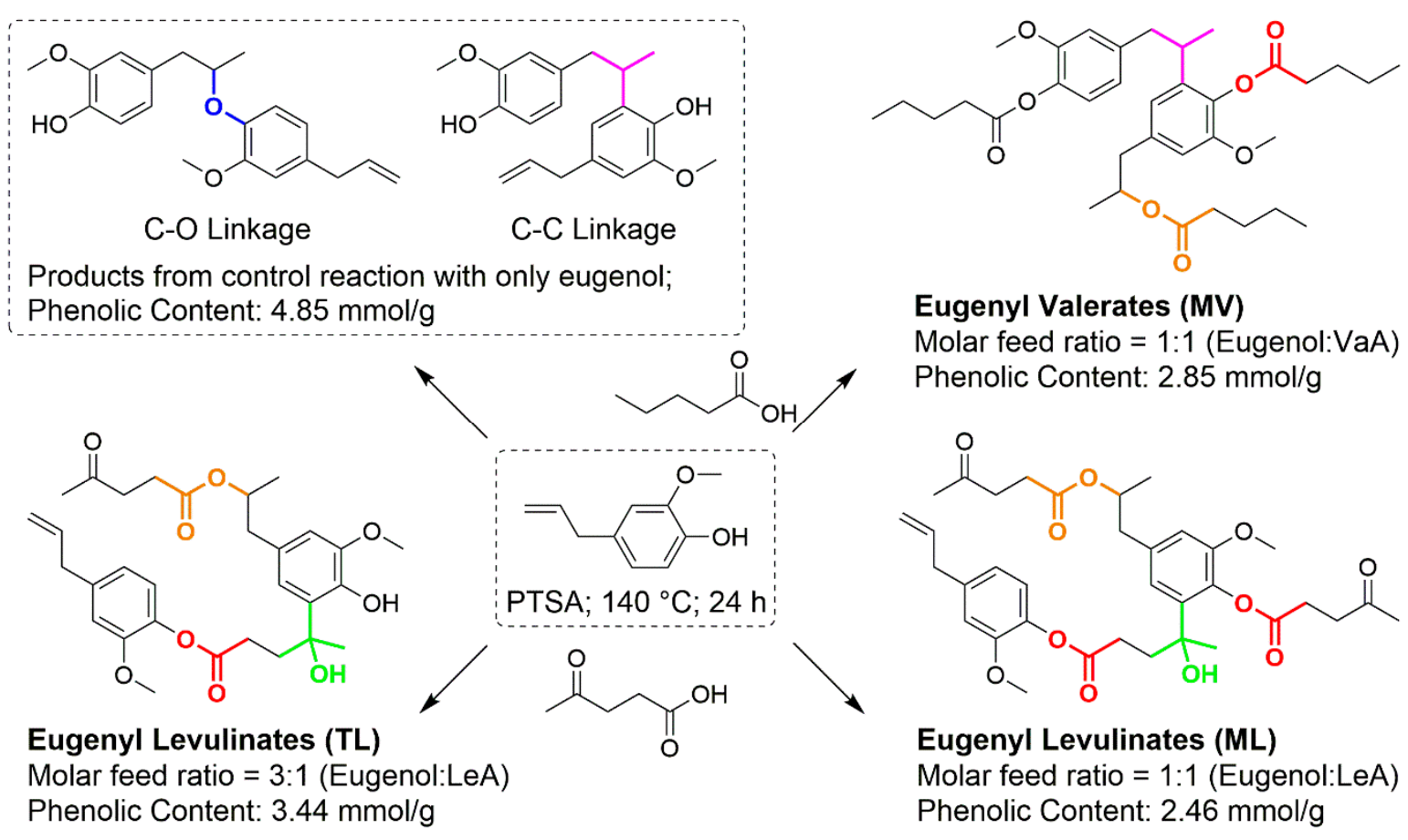

Figure 1. Schematic presentation of the synthesis, representative chemical bonds in the products, from a control reaction with eugenol only and the plasticizer candidates including eugenyl levulinates (ML and TL) and eugenyl valerate (MV) (C-O linkages in blue; C-C linkages in purple; phenolic ester bonds in red; aliphatic ester bonds in orange; converted-ketones in green).

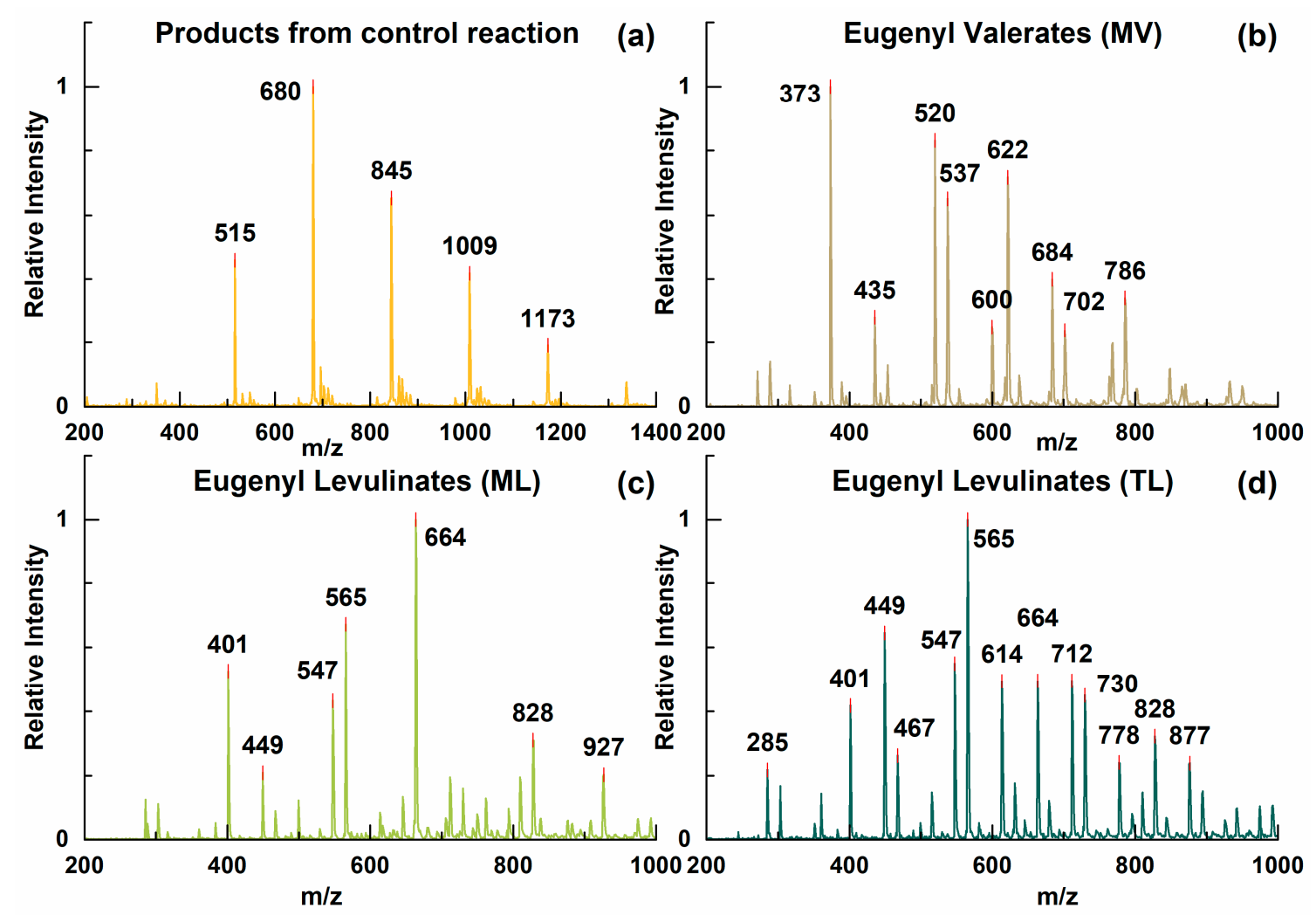

Figure 2. Electrospray ionization-mass spectra of products from a control reaction with only eugenol (a), eugenyl valerates-MV (b), eugenyl levulinates-ML (c) and eugenyl levulinates-TL (d). 
In principle, two classes of chemical bonds were formed in the control reaction with eugenol only and they are C-O linkages and C-C linkages, as shown in Figure 1. Eugenol oligomers were generated by those two means, as seen in the ESI-MS spectrum (Figure 2a). The allyl group in eugenol could be converted into carbocation with the presence of PTSA at high temperature. Termination of the carbocation formed C-O linkages (or C-C linkages) between allyl and phenolic hydroxyl groups (or aromatic rings). When valeric acid reacted with eugenol, the carboxyl groups in the valeric acid molecules were directly added to the double bonds in the allyl groups or encountered dehydrations with phenolic hydroxyl groups, both reactions resulted in the formation of ester bonds that were presented in the plasticizer candidate MV. C-O linkages and C-C linkages were also found in MV, and as a result, compounds with several connected aromatic rings were found in the ESI-MS spectrum (Figure 2b). Similarly, the carboxyl groups in levulinic acid reacted with allyl groups of eugenols and subsequently generated aliphatic and phenolic ester bonds in the plasticizer candidates ML and TL. The ESI-MS spectrum (Figure 2c,d) suggested more diverse products in ML and TL. The ketone groups in levulinic acids were subjected to nucleophilic addition and hence developed another type of linkage between aromatic rings and levulinic acids, which contributed to an alternative pathway to connect eugenols together with previous C-O and C-C linkages. In addition, due to this pathway, levulinic acids could be bridged to eugenols directly and cause the presence of carboxylic acid signals in ${ }^{31} \mathrm{P}$ NMR characterizations (Figure S22 and Table S2).

\subsection{Miscibility of PLA with Plasticizer Candidates}

PLA was blended with the plasticizer candidates $(10,20$ and $30 \mathrm{wt} \%)$ and the starting compounds (eugenol and levulinic acid) were casted into films. The transparent blend films, and a neat PLA film, were characterized by DSC to examine the miscibility of the plasticizer candidates with PLA and to characterize the thermal properties of the blends. Decreased $T_{g}$ values for all the PLA blends were observed, as compared to neat PLA. No recrystallization and melting process was observed, i.e., the PLA itself and its blends were both amorphous. Only one $T_{g}$ in each DSC diagram was observed (Figure 3 and Table S7). A depression of the $T_{g}$ further developed with an increasing amount of plasticizer, indicating that the improvement of PLA chain mobility because of the presence of plasticizer candidates. All three synthesized plasticizer candidates TL, ML and MV were miscible with PLA within the whole measurement range as indicated by the decreasing $T_{g}$ values as a function of plasticizer concentration. The lowest $T_{g}\left(16^{\circ} \mathrm{C}\right)$ was obtained when $30 \mathrm{wt} \%$ of plasticizer candidate MV was added, resulting in a $T_{g}$ below room temperature. The $T_{g}$ depressions for plasticizer candidate TL and ML were very close to each other at 10, 20 and $30 \mathrm{wt} \%$ concentrations. Although the PLA blends with $20 \mathrm{wt} \%$ neat eugenol or levulinic acid had similar $T_{g}$ values to PLA with $20 \mathrm{wt} \%$ TL or ML, the eugenol and levulinic acid blends portrayed phase separations after storage for a few weeks, i.e., eugenol and levulinic acids migrated from the materials bulk to the surface. The performances of the three plasticizer candidates were comparable to other naturally derived commercial plasticizers. For instance, PLA plasticized with $20 \mathrm{wt} \%$ commercial acetyl tributyl citrate (ATBC) [28] or di-2-etylhexyladipate (DOA) lowered the $T_{g}$ of PLA down to $23^{\circ} \mathrm{C}$ and $40{ }^{\circ} \mathrm{C}$, respectively [44]. As another example, a $T_{g}$ down to $28^{\circ} \mathrm{C}$ was obtained by addition of $10 \mathrm{wt} \%$ oregano essential oil which was enriched with phenolic compounds [45]. Additionally, the $T_{g}$ of PLA decreased to $52{ }^{\circ} \mathrm{C}$ [46], $49{ }^{\circ} \mathrm{C}$ [47] and $52{ }^{\circ} \mathrm{C}$ [47] by the addition of $10 \mathrm{wt} \%$ oligoesters, epoxidized linseed oil and epoxidized soybean oil, respectively. Previously hexanoates were produced from liquefied wood flour, which depressed the $T_{g}$ of PLA to $25{ }^{\circ} \mathrm{C}$ with $10 \mathrm{wt} \%$ addition [27]. These hexanoates had a close $\mathrm{M}_{\mathrm{W}}$ range comparable to TL, $\mathrm{ML}$ and $\mathrm{MV}$, and they also contained ring structures and free hydroxyl groups from monosaccharides and disaccharides, which were similar to the eugenol structures in the three synthesized plasticizer candidates. 


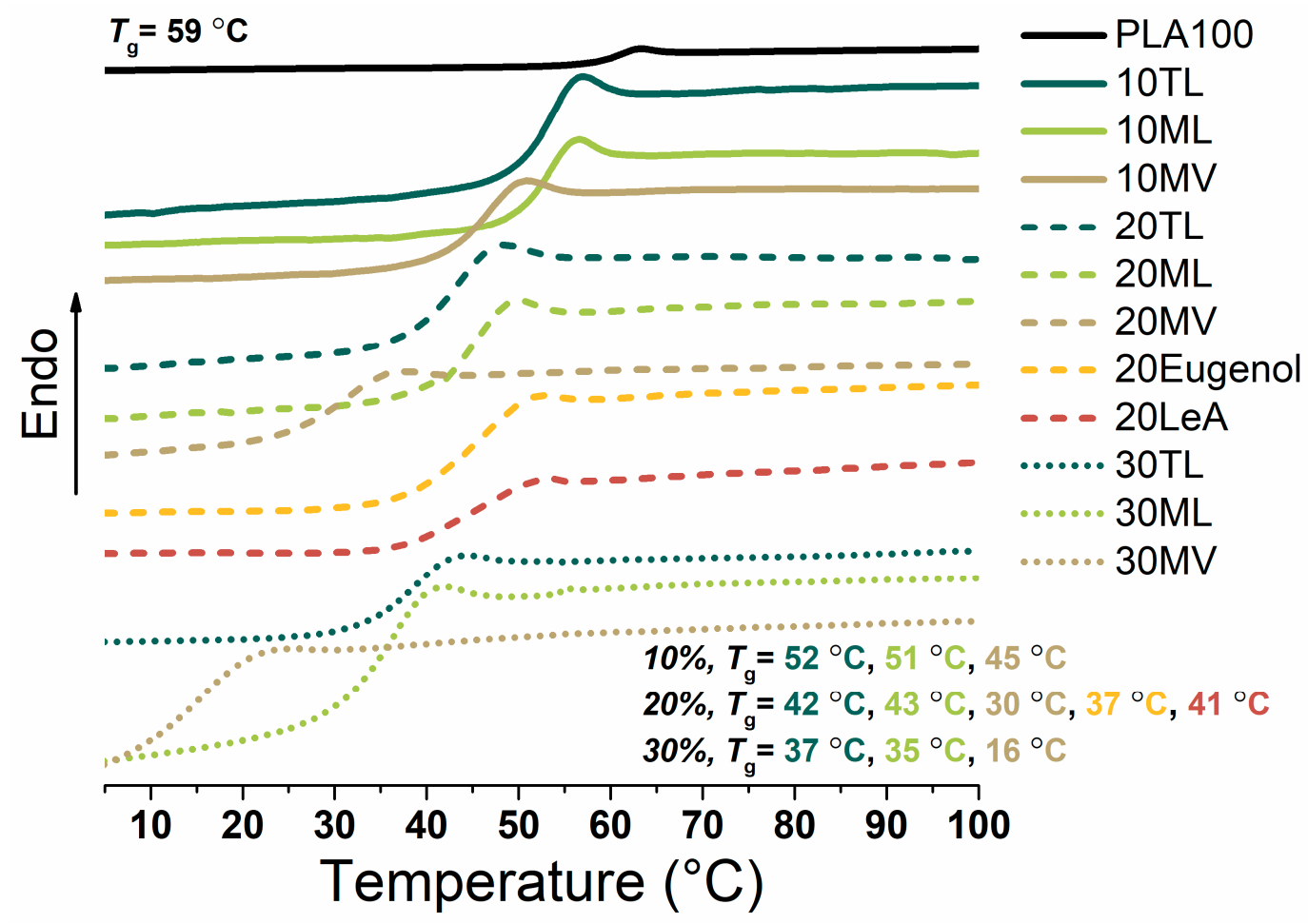

Figure 3. Differential scanning calorimetry (DSC) thermograms for neat PLA and the different blends.

\subsection{Thermal Stability of PLA Blends with Plasticizer Candidates}

PLA blends with the plasticizer candidates were further characterized by gravimetric analysis to assess the thermal stabilities of the blends which were indicated by the degradation temperatures where $5 \mathrm{wt} \%$ mass loss occurred (T5). The higher T5 temperature suggested better thermal stability of the blend. The results are illustrated in Figure 4 and Table S8. PLA blends with ML demonstrated higher thermal stability with higher T5 values as compared to the blends with TL and MV. With 20 or $30 \mathrm{wt} \%$ addition of the plasticizer candidates, PLA blends with ML and TL portrayed similar degradation curves. However, $10 \mathrm{ML}$ demonstrated significantly higher thermal stability compared to that of $10 \mathrm{TL}$. The blend $10 \mathrm{MV}$ had the lowest $\mathrm{T} 5$ value $\left(179^{\circ} \mathrm{C}\right)$, as compared to $207^{\circ} \mathrm{C}$ for $10 \mathrm{ML}$ and $198^{\circ} \mathrm{C}$ for $10 \mathrm{TL}$. When the amount of plasticizer candidate MV increased to $30 \mathrm{wt} \%$, the thermal stability of $30 \mathrm{MV}$ significantly deteriorated, although its $\mathrm{T} 5$ value was still $182^{\circ} \mathrm{C}$, which could still allow melt-processing of the material. In addition, two stages of thermal degradation were observed in 20 Eugenol and 20 LeA (Figure 4), including the evaporation of eugenol and LeA in the first step and the degradation of PLA in the second step. That evaporation process had also been recorded in Figure S23 and Table S9. 


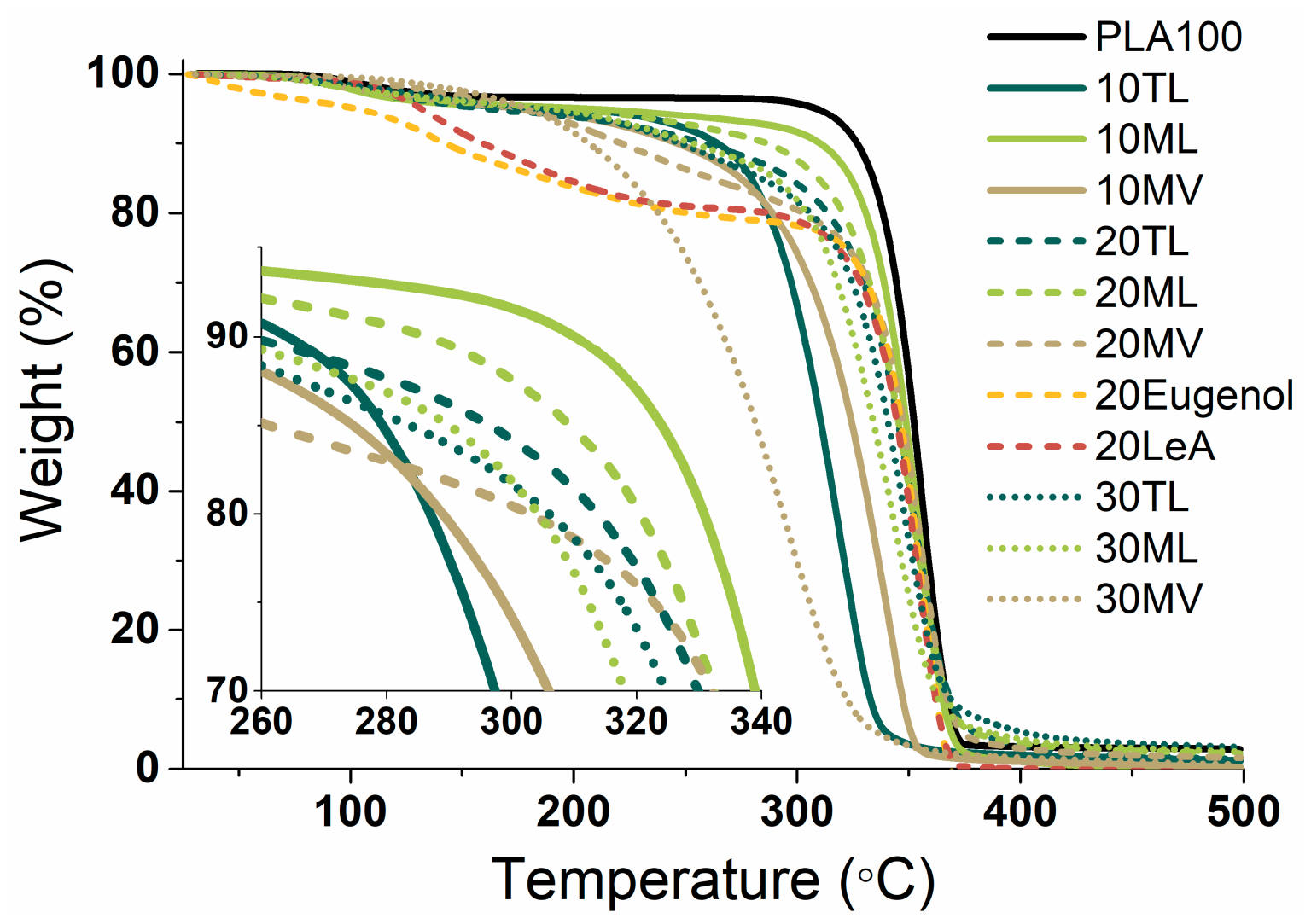

Figure 4. TGA curves of neat PLA and its blends.

\subsection{Mechanical Performance of PLA Blends with Plasticizer Candidates}

The PLA blends were examined by tensile testing to determine the plasticizing effect of the three synthesized plasticizer candidates and to evaluate the mechanical properties after the addition of the plasticizer candidates. As expected, the mechanical properties of PLA were altered by the addition of plasticizer candidates, which all had good affinity to PLA and lowered the $T_{g}$ of PLA. A common trend for all PLA blends with increasing concentration of plasticizer candidates was that, due to the improved chain mobility, the Young's modulus and tensile stress at break decreased while the tensile strain at break increased. This is demonstrated in Figure 5 and Figures S24-S35 and Table S10. The bubbles in Figure 5 symbolized the tensile stress at break of the blends and their values were reflected by the relative size of the bubbles, which were compared to that of neat PLA. The size of the bubble generally decreased after the addition of the plasticizer candidates. For $20 \mathrm{TL}$, as an example, the Young's modulus, strain at break and stress at break were $1.4 \mathrm{GPa}, 330 \%$ and $24 \mathrm{MPa}$ respectively, whereas the values were $1.9 \mathrm{GPa}, 91 \%$ and $21 \mathrm{MPa}$ for $10 \mathrm{TL}$. In contrast to that, the PLA100 had a Young's modulus of $2.1 \mathrm{GPa}$ and a value of stress at break of $57 \mathrm{MPa}$, with a strain at break of 5.4\% [28]. Hence, all PLA blends with the three different plasticizer candidates were plasticized. Although PLA blends with $20 \mathrm{wt} \%$ eugenol or levulinic acid suggested plasticization as well, their modulus was rather poor as compared to the performances of the eugenol and levulinic acid-derived plasticizer candidates. Furthermore, phase separation was observed in all PLA blends with 20\% eugenol or $20 \%$ levulinic acid some days after tensile testing. Part of the films became rigid and the surface of the films became sticky, indicating migration of plasticizer to the surface. 


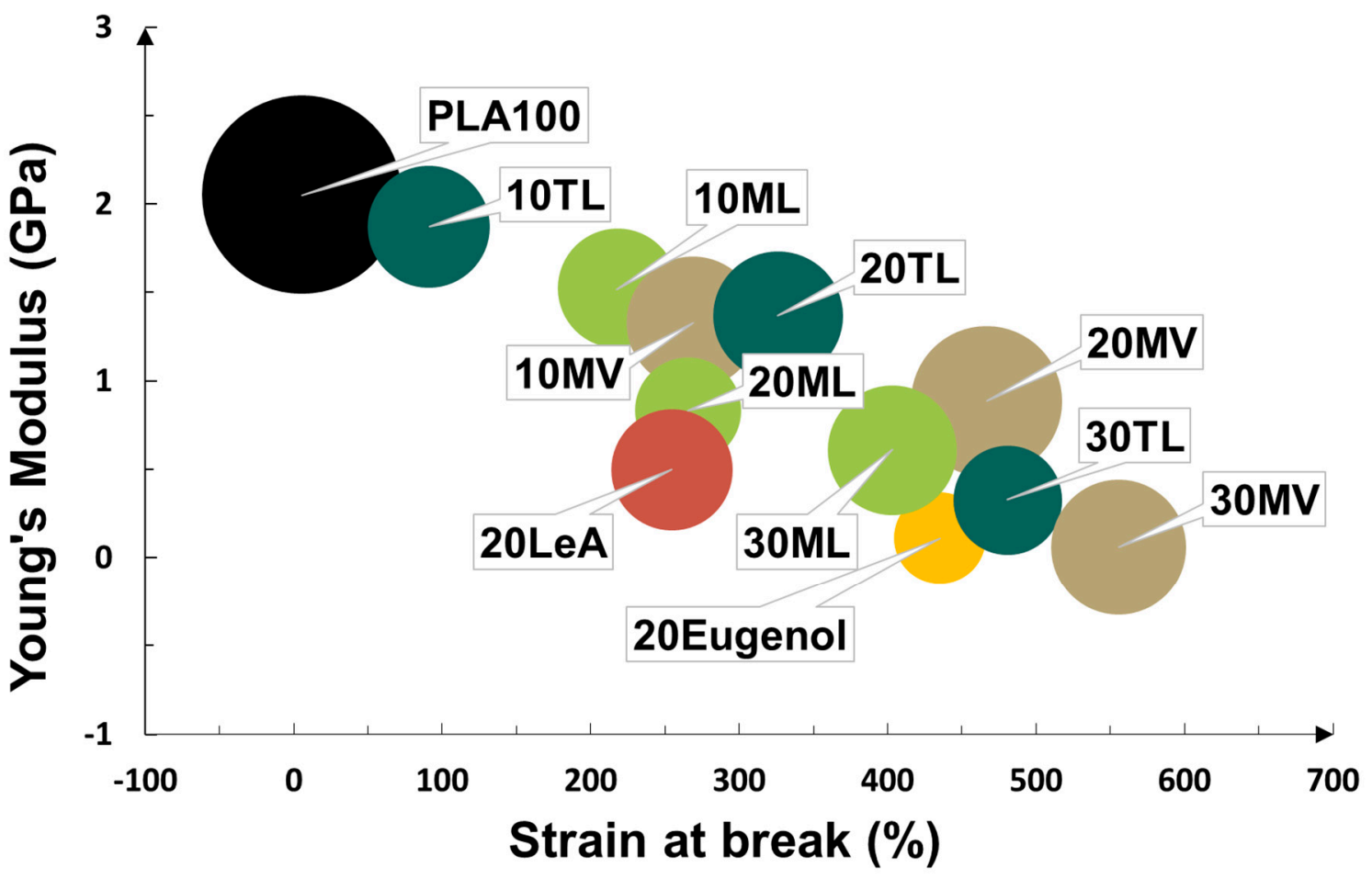

Figure 5. Mechanical properties of PLA blends (the relative bubble size symbolizes stress at break values).

Interestingly, the $T_{g}$ of the PLA blends plasticized by TL and ML indicated that they had a very similar ability to enhance the chain mobility of PLA, since the $T_{g}$ of their blends were very similar at the same plasticizer concentration. However, the plasticizer candidate TL resulted in higher strain at break compared to ML at 20 and $30 \mathrm{wt} \%$ addition. The levulinic acid content was significantly higher in ML plasticizer compared to TL, which led to lower strain at break. This agrees with the higher strain at break for the blend containing only $20 \mathrm{wt} \%$ eugenol compared to the blend containing only $20 \mathrm{wt} \%$ levulinic acid, i.e., eugenol was initially more effective plasticizer than levulinic acid. Although, it should be mentioned that the eugenol plasticized films were not stable with time and there were significant migration problems. Noticeably, addition of plasticizer candidate MV resulted in the largest improvement in strain at break at each concentration among the three plasticizer candidates. The dominant structure in MV had a lower molecular weight $(\mathrm{Mw}=350)$ than the ones in TL $(\mathrm{Mw}=641)$ and ML (Mw =542). The smaller Mw for the plasticizer enables a higher diffusion rate in polymers and a higher number of plasticizer molecules when the same $w \mathrm{t} \%$ of plasticizer is used, which usually leads to higher strain at break [23]. From the aspect of chemical structure, the balance between polar and nonpolar groups is important for the plasticization efficiency [37]. The MV plasticizer has the lowest level of hydroxyl and carbonyl groups in its structure as compared to TL and ML and ester bonds are the predominant linkages in it. This probably ensured more interactions with the ester groups in the PLA backbone. Furthermore, the TL plasticizer had a longer flexible nonpolar alkane chain, which is expected to improve the plastification. The higher amount of polar groups in TL and ML could also result in stronger secondary interactions between the plasticizer molecules, which could further lower the plasticizing efficiency due to the weaker affinity between PLA and plasticizer molecules [23].

With $20 \mathrm{wt} \%$ addition of ATBC, the plasticized PLA film demonstrated a Young's modulus of $0.26 \mathrm{GPa}$ and could be elongated to $640 \%$ with a stress of $49 \mathrm{MPa}$ at break [28]. As compared to the blends with $20 \mathrm{wt} \%$ ATBC, the blends with $20 \mathrm{wt} \%$ eugenol-based plasticizer TL, ML and MV all had a higher Young's modulus and their strain at break values were lower, ranging from 260 to $470 \%$. This enables the possibility to tune mechanical properties based on the application requirements. Moreover, the 20 TL blend had an equal Young's modulus and somewhat higher strain and stress at break than PLA blended with $20 \mathrm{wt} \%$ DOA, another commercial biobased plasticizer [44]. Therefore, 
the achieved mechanical performances of the PLA blends with the three synthesized plasticizers were adequate compared to commercial biobased plasticizers for PLA. Furthermore, comparison against reported studies on other biobased plasticizers shows that the overall performances of the three synthesized eugenol-based plasticizers were comparable. For example, $10 \mathrm{wt} \%$ oregano essential oil that contains phenolic compounds increased the strain at break of PLA to $338 \%$, while the modulus and tensile strength were $1.45 \mathrm{GPa}$ and $29.4 \mathrm{MPa}$, respectively [45]. With the presence of $20 \mathrm{wt} \%$ derivatives of cardanol containing phenolic ester bonds, the tensile stress of PLA declined to $18 \mathrm{MPa}$ by cardanol acetate and to $10 \mathrm{MPa}$ by epoxidized cardanol acetate, meanwhile the tensile strain was increased to $37 \%$ by cardanol acetate and to $18 \%$ by epoxidized cardanol acetate [48]. In addition, $20 \mathrm{wt} \%$ oligoesters enabled the tensile stress and tensile strain of PLA to rise to $30 \mathrm{MPa}$ and $14 \%$, respectively [46].

\subsection{Antibacterial Properties of The Synthesized Plasticizers}

The bactericidal activity of the plasticizers TL, ML and MV were assessed by a zone of inhibition test against Gram-positive Staphylococcus aureus (S. aureus) and Gram-negative Escherichia coli (E. coli) in three different forms-PLA disks plasticized by 10 and $20 \mathrm{wt} \%$ plasticizer, paper disks loaded with 1 or $5 \mathrm{mg}$ plasticizers and spots with neat plasticizers. The results indicated that the plasticizer TL exhibited stronger bactericidal activity for both E. coli and S. aureus, as compared to plasticizer ML and MV that demonstrated bactericidal activity only for S. aureus (Figures 6 and 7). The bactericidal activity on an agar plate was affected by the diffusion conditions of plasticizers on the agar plate (migration rate of plasticizer from PLA blend and water solubility of the plasticizer), the concentration of plasticizer and the intrinsic antibacterial capability of the plasticizer. As seen in Figure 6, part of the plasticizer droplets did not level and spread uniformly on the surface of agar plates due to the high viscosity of the plasticizer. The diffusion ability of each plasticizer also varied due to the chemical structure. The weight, volume and shape of each droplet were not the same. As a consequence, only qualitative bactericidal activity of the plasticizer was obtained. The gap distances between the droplets and inhibition zones were presented in Figure 6 and Table S11. The migration behavior of a plasticizer is influenced by its structure [49-52], and, due to the limited migration of the plasticizers from PLA blends, no clear inhibition zone was observed in Figure S36. Therefore, the bactericidal activity of the plasticizer was further evaluated by testing paper disks loaded with 1 or $5 \mathrm{mg}$ of plasticizers. As expected, a higher concentration of antibacterial plasticizer resulted in a larger inhibition zone on the agar plate (Figure 7 and Table S12). Generally, phenolic hydroxyl groups and alcohol groups are both considered as active functionalities for antibacterial effects [53,54]. The former was widely present in all three plasticizers and the latter existed in TL with a significantly higher concentration as compared to plasticizers ML and MV, according to Table S2. In agreement, plasticizer TL, with the highest content of phenolic hydroxyl groups and alcohol groups, had the highest bactericidal activity among the three plasticizers. Moreover, plasticizer TL also had the highest content of carboxylic groups, which might lead to improved water solubility and strengthen the bactericidal activity due to the dissociation of protons. 


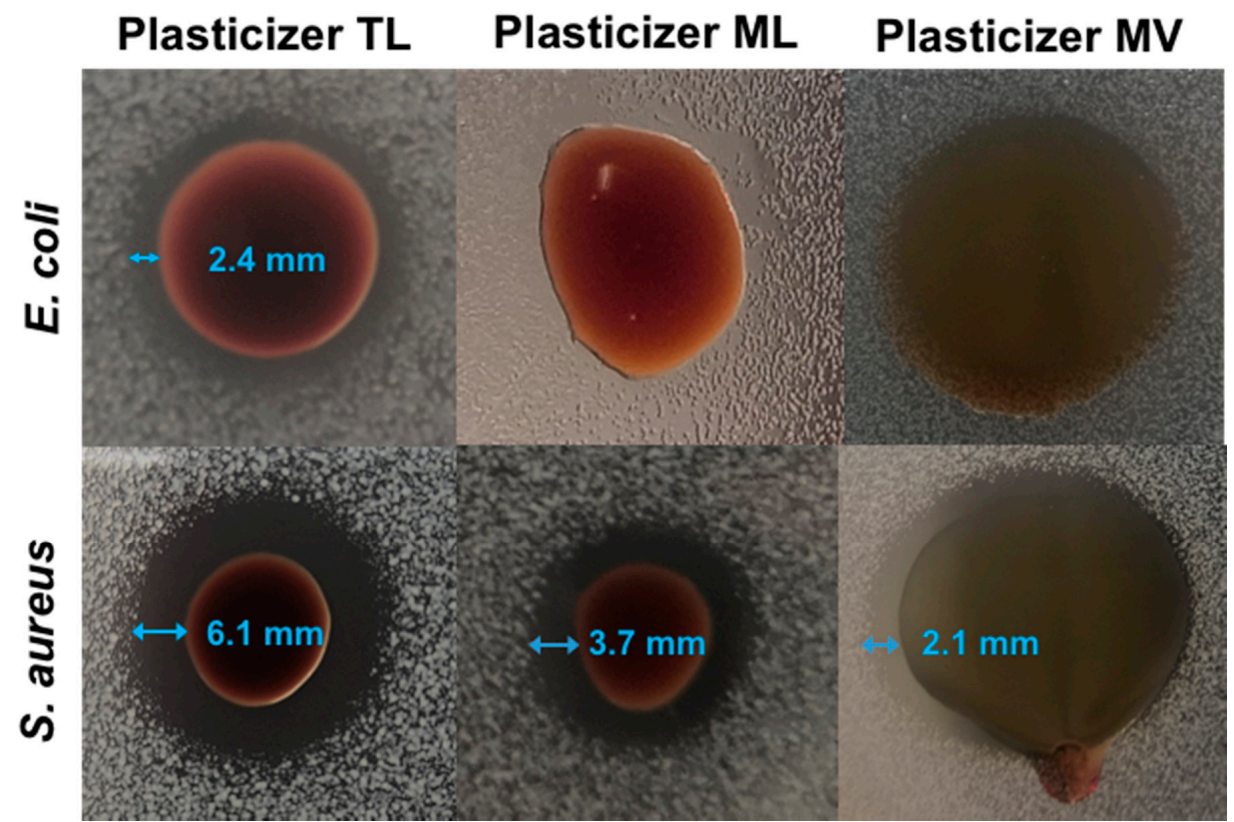

Figure 6. Zone of inhibition test on neat plasticizers against E. coli and S. aureus.

TL
ML

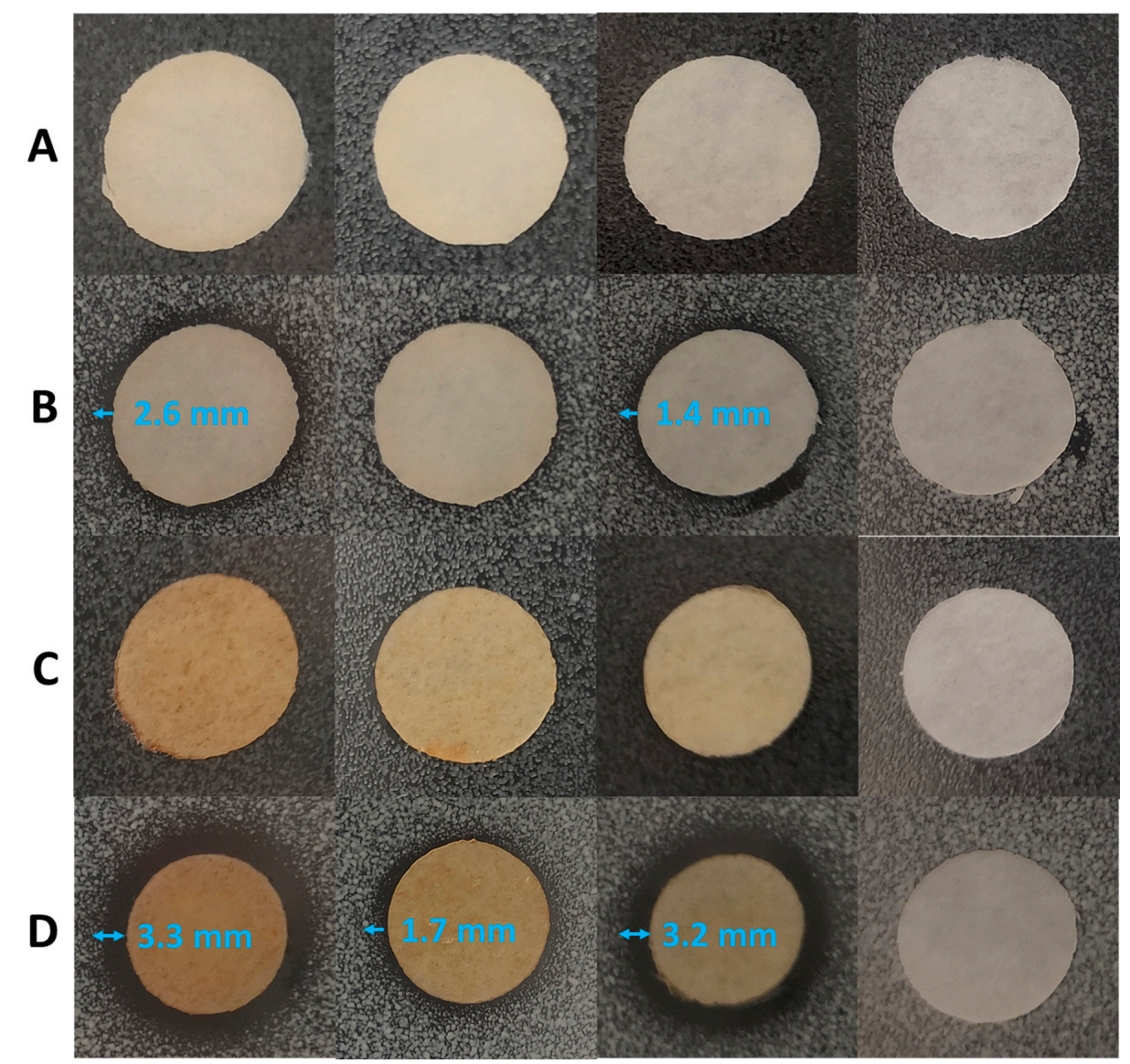

MV

Control

Figure 7. Zone of inhibition test for the plasticizers loaded on paper disks against $E$. coli and S. aureus (A: $1 \mathrm{mg}$ of plasticizers and E. coli; B: $1 \mathrm{mg}$ of plasticizers and S. aureus; C: $5 \mathrm{mg}$ of plasticizers and E. coli; D: $5 \mathrm{mg}$ of plasticizers and S. aureus). 


\section{Conclusions}

Three eugenol-based plasticizers were successfully prepared by a one-pot reaction between eugenol and the green platform chemical levulinic acid, or eugenol and valeric acid. The complicated structures of the synthesized plasticizes were defined by a library of techniques $\left({ }^{1} \mathrm{H}\right.$ NMR, ${ }^{13} \mathrm{C}$ NMR, ${ }^{31}$ P NMR, HSQC, COSY, HMBC and ESI-MS). The relationship between polar and nonpolar groups in the chemical structure and the molecular weight of the synthesized plasticizers governed the plasticization efficiency and the mechanical properties of the resulting PLA blends. The $T_{\mathrm{g}}$ of all plasticized PLA blends decreased considerably compared to neat PLA. All the synthesized plasticizers also increased the strain at break of PLA. The MV (eugenyl valerate) plasticizer enabled the largest depression in $T_{\mathrm{g}}$ and largest strain at break compared to other PLA blends with same plasticizer concentration. This is put down to lower molecular weight, the highest concentration of ester groups for forming secondary interactions with PLA as well as a longer flexible alkane chain, assumed to lead to higher plasticization effect. The antibacterial assessment proved the bactericidal activity of the three plasticizers against Staphylococcus aureus. The plasticizer eugenyl levulinate also inhibited the growth of Escherichia coli in zone of inhibition tests. Hence, the plasticizers derived from eugenol and levulinic acid demonstrated favorable dual functions to act as antibacterial plasticizers for PLA.

Supplementary Materials: The following are available online at http://www.mdpi.com/2218-273X/10/7/1077/s1, Figures S1-S22 and Tables S1-S6: The structural analyses of plasticizer MV, ML and TL; Figure S23 and Tables S7-S9: Thermal stability of plasticizers and their PLA blends; Figures S24-S35 and Table S10: Mechanical performance of plasticized PLA; Figure S36 and Tables S11, S12: Antibacterial study of the plasticizers.

Author Contributions: Conceptualization, W.X., K.O., M.H.; Investigation, W.X.; Methodology, W.X., K.O., M.H.; Writing-original draft, W.X.; Writing—review and editing, W.X., K.O., M.H. All authors read and approved the final manuscript.

Funding: Wenxiang Xuan thankfully acknowledges funding from The China Scholarship Council (CSC).

Acknowledgments: The authors acknowledge Yanmiao Fan, Karin Adolfsson and Shirin Khaliliazar for the guidance on the antibacterial evaluation and Tove Kivijärvi for the support on 2D-NMR analyses.

Conflicts of Interest: The authors declare no conflict of interest.

\section{References}

1. Haugaard, V.K.; Frederiksen, C.S.; Poll, L.; Miquel Becker, E. Light-induced quality changes in plain yoghurt packed in polylactate and polystyrene. Eur. Food Res. Technol. 2003, 217, 61-69. [CrossRef]

2. Haugaard, V.; Weber, C.; Danielsen, B.; Bertelsen, G. Quality changes in orange juice packed in materials based on polylactate. Eur. Food Res. Technol. 2002, 214, 423-428. [CrossRef]

3. Koide, S.; Shi, J. Microbial and quality evaluation of green peppers stored in biodegradable film packaging. Food Control 2007, 18, 1121-1125. [CrossRef]

4. Haugaard, V.K.; Danielsen, B.; Bertelsen, G. Impact of polylactate and poly(hydroxybutyrate) on food quality. Eur. Food Res. Technol. 2003, 216, 233-240. [CrossRef]

5. Holm, V.; Mortensen, G.; Risbo, J. Quality changes in semi-hard cheese packaged in a poly(lactic acid) material. Food Chem. 2006, 97, 401-410. [CrossRef]

6. Joo, M.; Lewandowski, N.; Auras, R.; Harte, J.; Almenar, E. Comparative shelf life study of blackberry fruit in bio-based and petroleum-based containers under retail storage conditions. Food Chem. 2011, 126, 1734-1740. [CrossRef]

7. Conn, R.E.; Kolstad, J.J.; Borzelleca, J.F.; Dixler, D.S.; Filer, L.J.; Ladu, B.N.; Pariza, M.W. Safety assessment of polylactide (PLA) for use as a food-contact polymer. Food Chem. Toxicol. 1995, 33, 273-283. [CrossRef]

8. Vink, E.T.H.; Rábago, K.R.; Glassner, D.A.; Springs, B.; O'Connor, R.P.; Kolstad, J.; Gruber, P.R. The Sustainability of NatureWorks ${ }^{\mathrm{TM}}$ Polylactide Polymers and Ingeo ${ }^{\mathrm{TM}}$ Polylactide Fibers: An Update of the Future. Macromol. Biosci. 2004, 4, 551-564. [CrossRef]

9. Catalá, R.; López-Carballo, G.; Hernández-Muñoz, P.; Gavara, R. PLA and Active Packaging. In Poly(lactic acid) Science and Technology: Processing, Properties, Additives and Applications; RSC Publishing: Cambridge, UK, 2014; Chapter 10; pp. 243-265, ISBN 9781782624806. 
10. Arrieta, M.P.; Castro-López, M.D.M.; Rayón, E.; Barral-Losada, L.F.; López-Vilariño, J.M.; López, J.; González-Rodríguez, M.V. Plasticized Poly(lactic acid)-Poly(hydroxybutyrate) (PLA-PHB) Blends Incorporated with Catechin Intended for Active Food-Packaging Applications. J. Agric. Food Chem. 2014, 62, 10170-10180. [CrossRef]

11. Jin, T.; Liu, L.; Zhang, H.; Hicks, K. Antimicrobial activity of nisin incorporated in pectin and polylactic acid composite films against Listeria monocytogenes. Int. J. Food Sci. Technol. 2009, 44, 322-329. [CrossRef]

12. Jin, T. Inactivation of Listeria monocytogenes in Skim Milk and Liquid Egg White by Antimicrobial Bottle Coating with Polylactic Acid and Nisin. J. Food Sci. 2010, 75, M83-M88. [CrossRef] [PubMed]

13. Longano, D.; Ditaranto, N.; Cioffi, N.; Di Niso, F.; Sibillano, T.; Ancona, A.; Conte, A.; Del Nobile, M.A.; Sabbatini, L.; Torsi, L. Analytical characterization of laser-generated copper nanoparticles for antibacterial composite food packaging. Anal. Bioanal. Chem. 2012, 403, 1179-1186. [CrossRef] [PubMed]

14. Busolo, M.A.; Fernandez, P.; Ocio, M.J.; Lagaron, J.M. Novel silver-based nanoclay as an antimicrobial in polylactic acid food packaging coatings. Food Addit. Contam. Part A 2010, 27, 1617-1626. [CrossRef]

15. Jin, T.; Zhang, H.; Boyd, G. Incorporation of Preservatives in Polylactic Acid Films for Inactivating Escherichia coli O157:H7 and Extending Microbiological Shelf Life of Strawberry Puree. J. Food Prot. 2010, 73, 812-818. [CrossRef]

16. Theinsathid, P.; Visessanguan, W.; Kruenate, J.; Kingcha, Y.; Keeratipibul, S. Antimicrobial Activity of Lauric Arginate-Coated Polylactic Acid Films against Listeria monocytogenes and Salmonella Typhimurium on Cooked Sliced Ham. J. Food Sci. 2012, 77, 142-149. [CrossRef] [PubMed]

17. Salmieri, S.; Islam, F.; Khan, R.A.; Hossain, F.M.; Ibrahim, H.M.M.; Miao, C.; Hamad, W.Y.; Lacroix, M. Antimicrobial nanocomposite films made of poly(lactic acid)-cellulose nanocrystals (PLA-CNC) in food applications-Part B: Effect of oregano essential oil release on the inactivation of Listeria monocytogenes in mixed vegetables. Cellulose 2014, 21, 4271-4285. [CrossRef]

18. Wu, Y.; Qin, Y.; Yuan, M.; Li, L.; Chen, H.; Cao, J.; Yang, J. Characterization of an antimicrobial poly(lactic acid) film prepared with poly ( $\varepsilon$-caprolactone) and thymol for active packaging. Polym. Adv. Technol. 2014, 25, 948-954. [CrossRef]

19. González, A.; Alvarez Igarzabal, C.I. Soy protein-Poly (lactic acid) bilayer films as biodegradable material for active food packaging. Food Hydrocoll. 2013, 33, 289-296. [CrossRef]

20. Kayaci, F.; Umu, O.C.O.; Tekinay, T.; Uyar, T. Antibacterial Electrospun Poly(lactic acid) (PLA) Nanofibrous Webs Incorporating Triclosan/Cyclodextrin Inclusion Complexes. J. Agric. Food Chem. 2013, 61, 3901-3908. [CrossRef]

21. Bie, P.; Liu, P.; Yu, L.; Li, X.; Chen, L.; Xie, F. The properties of antimicrobial films derived from poly(lactic acid)/starch/chitosan blended matrix. Carbohydr. Polym. 2013, 98, 959-966. [CrossRef] [PubMed]

22. Saeidlou, S.; Huneault, M.A.; Li, H.; Park, C.B. Poly(lactic acid) crystallization. Prog. Polym. Sci. 2012, 37, 1657-1677. [CrossRef]

23. Immergut, E.H.; Mark, H.F. Principles of Plasticization. In Plasticization and Plasticizer Processes; ACS Publications: Washington, DC, USA, 1965; pp. 1-26.

24. Yang, X.; Hakkarainen, M. Migration resistant glucose esters as bioplasticizers for polylactide. J. Appl. Polym. Sci. 2015, 132, 1-8. [CrossRef]

25. Yang, X.; Xu, H.; Odelius, K.; Hakkarainen, M. Poly(lactide)-g-poly(butylene succinate-co-adipate) with High Crystallization Capacity and Migration Resistance. Materials (Basel) 2016, 9, 313. [CrossRef] [PubMed]

26. Yang, X.; Clénet, J.; Xu, H.; Odelius, K.; Hakkarainen, M. Two Step Extrusion Process: From Thermal Recycling of PHB to Plasticized PLA by Reactive Extrusion Grafting of PHB Degradation Products onto PLA Chains. Macromolecules 2015, 48, 2509-2518. [CrossRef]

27. Azwar, E.; Yin, B.; Hakkarainen, M. Liquefied biomass derived plasticizer for polylactide. J. Chem. Technol. Biotechnol. 2013, 88, 897-903. [CrossRef]

28. Xuan, W.; Hakkarainen, M.; Odelius, K. Levulinic Acid as a Versatile Building Block for Plasticizer Design. ACS Sustain. Chem. Eng. 2019, 7, 12552-12562. [CrossRef]

29. U.S. Food and Drug Administration. Title 21: Food and Drugs; PART 181-PRIOR-SANCTIONED FOOD INGREDIENTS; Subpart B-Specific Prior-Sanctioned Food Ingredients; \$181.27 Plasticizers; U.S. Department of Health and Human Services: Washington, DC, USA, 2020.

30. U.S. Food and Drug Administration. Inventory of Effective Food Contact Substance (FCS) Notifications. Available online: https://www.accessdata.fda.gov/scripts/fdcc/?set=FCN\&sort= FCN_No\&order=DESC\&startrow=1\&type=advanced\&search=æxplasticizeræ (accessed on 22 April 2020). 
31. Jamshidian, M.; Arab Tehrany, E.; Cleymand, F.; Leconte, S.; Falher, T.; Desobry, S. Effects of synthetic phenolic antioxidants on physical, structural, mechanical and barrier properties of poly lactic acid film. Carbohydr. Polym. 2012, 87, 1763-1773. [CrossRef]

32. Jamshidian, M.; Tehrany, E.A.; Desobry, S. Antioxidants Release from Solvent-Cast PLA Film: Investigation of PLA Antioxidant-Active Packaging. Food Bioprocess Technol. 2013, 6, 1450-1463. [CrossRef]

33. Rigoussen, A.; Verge, P.; Raquez, J.-M.; Dubois, P. Natural Phenolic Antioxidants As a Source of Biocompatibilizers for Immiscible Polymer Blends. ACS Sustain. Chem. Eng. 2018, 6, 13349-13357. [CrossRef]

34. Fiuza, S.M.; Gomes, C.; Teixeira, L.J.; Girão Da Cruz, M.T.; Cordeiro, M.N.D.S.; Milhazes, N.; Borges, F.; Marques, M.P.M. Phenolic acid derivatives with potential anticancer properties-A structure-activity relationship study. Part 1: Methyl, propyl and octyl esters of caffeic and gallic acids. Bioorganic Med. Chem. 2004, 12, 3581-3589. [CrossRef]

35. Bakkali, F.; Averbeck, S.; Averbeck, D.; Idaomar, M. Biological effects of essential oils-A review. Food Chem. Toxicol. 2008, 46, 446-475. [CrossRef] [PubMed]

36. Liberatore, H.K.; Plewa, M.J.; Wagner, E.D.; VanBriesen, J.M.; Burnett, D.B.; Cizmas, L.H.; Richardson, S.D. Identification and Comparative Mammalian Cell Cytotoxicity of New Iodo-Phenolic Disinfection Byproducts in Chloraminated Oil and Gas Wastewaters. Environ. Sci. Technol. Lett. 2017, 4, 475-480. [CrossRef]

37. Jamarani, R.; Erythropel, H.; Nicell, J.; Leask, R.; Marić, M. How Green is Your Plasticizer? Polymers 2018, 10, 834. [CrossRef] [PubMed]

38. Rahman, M.; Brazel, C. The plasticizer market: An assessment of traditional plasticizers and research trends to meet new challenges. Prog. Polym. Sci. 2004, 29, 1223-1248. [CrossRef]

39. Vandenberg, L.N.; Hauser, R.; Marcus, M.; Olea, N.; Welshons, W.V. Human exposure to bisphenol A (BPA). Reprod. Toxicol. 2007, 24, 139-177. [CrossRef]

40. Heudorf, U.; Mersch-Sundermann, V.; Angerer, J. Phthalates: Toxicology and exposure. Int. J. Hyg. Environ. Health 2007, 210, 623-634. [CrossRef]

41. Burt, S. Essential oils: Their antibacterial properties and potential applications in foods-A review. Int. J. Food Microbiol. 2004, 94, 223-253. [CrossRef]

42. Gazzotti, S.; Hakkarainen, M.; Adolfsson, K.H.; Ortenzi, M.A.; Farina, H.; Lesma, G.; Silvani, A. One-Pot Synthesis of Sustainable High-Performance Thermoset by Exploiting Eugenol Functionalized 1,3-Dioxolan-4-one. ACS Sustain. Chem. Eng. 2018, 6, 15201-15211. [CrossRef]

43. Bozell, J.J.; Petersen, G.R. Technology development for the production of biobased products from biorefinery carbohydrates-the US Department of Energy's “Top 10" revisited. Green Chem. 2010, 12, 539. [CrossRef]

44. Martino, V.P.; Jiménez, A.; Ruseckaite, R.A. Processing and characterization of poly(lactic acid) films plasticized with commercial adipates. J. Appl. Polym. Sci. 2009, 112, 2010-2018. [CrossRef]

45. Llana-Ruiz-Cabello, M.; Pichardo, S.; Bermúdez, J.M.; Baños, A.; Núñez, C.; Guillamón, E.; Aucejo, S.; Cameán, A.M. Development of PLA films containing oregano essential oil ( Origanum vulgare L. virens ) intended for use in food packaging. Food Addit. Contam. Part A 2016, 33, 1-13. [CrossRef] [PubMed]

46. Santos, E.F.; Oliveira, R.V.B.; Reiznautt, Q.B.; Samios, D.; Nachtigall, S.M.B. Sunflower-oil biodiesel-oligoesters/polylactide blends: Plasticizing effect and ageing. Polym. Test. 2014, 39, 23-29. [CrossRef]

47. Orue, A.; Eceiza, A.; Arbelaiz, A. Preparation and characterization of poly(lactic acid) plasticized with vegetable oils and reinforced with sisal fibers. Ind. Crop. Prod. 2018, 112, 170-180. [CrossRef]

48. Greco, A.; Ferrari, F.; Maffezzoli, A. Mechanical properties of poly(lactid acid) plasticized by cardanol derivatives. Polym. Degrad. Stab. 2019, 159, 199-204. [CrossRef]

49. Höglund, A.; Hakkarainen, M.; Albertsson, A.C. Migration and hydrolysis of hydrophobic polylactide plasticizer. Biomacromolecules 2010, 11, 277-283. [CrossRef] [PubMed]

50. Hakkarainen, M. Migration of Monomeric and Polymeric PVC Plasticizers. In Chromatography for Sustainable Polymeric Materials; Springer Berlin Heidelberg: Berlin, Heidelberg, Germany, 2008; Volume 211, pp. 159-185. ISBN 9783540787624.

51. Lindström, A.; Hakkarainen, M. Designed chain architecture for enhanced migration resistance and property preservation in poly(vinyl chloride)/polyester blends. Biomacromolecules 2007, 8, 1187-1194. [CrossRef] [PubMed]

52. Andersson, S.R.; Hakkarainen, M.; Albertsson, A.C. Tuning the polylactide hydrolysis rate by plasticizer architecture and hydrophilicity without introducing new migrants. Biomacromolecules 2010, 11, 3617-3623. [CrossRef] [PubMed] 
53. Sacchetti, G.; Maietti, S.; Muzzoli, M.; Scaglianti, M.; Manfredini, S.; Radice, M.; Bruni, R. Comparative evaluation of 11 essential oils of different origin as functional antioxidants, antiradicals and antimicrobials in foods. Food Chem. 2005, 91, 621-632. [CrossRef]

54. Bruni, R.; Medici, A.; Andreotti, E.; Fantin, C.; Muzzoli, M.; Dehesa, M.; Romagnoli, C.; Sacchetti, G. Chemical composition and biological activities of Ishpingo essential oil, a traditional Ecuadorian spice from Ocotea quixos (Lam.) Kosterm. (Lauraceae) flower calices. Food Chem. 2004, 85, 415-421. [CrossRef]

(C) 2020 by the authors. Licensee MDPI, Basel, Switzerland. This article is an open access article distributed under the terms and conditions of the Creative Commons Attribution (CC BY) license (http://creativecommons.org/licenses/by/4.0/). 